EPJ Web of Conferences 52, 04006 (2013)

DOI: 10.1051/epjconf/20135204006

(C) Owned by the authors, published by EDP Sciences, 2013

\title{
Energy spectrum of primary cosmic rays in a wide range of energy
}

Janusz Kempa ${ }^{1, a}$

${ }^{1}$ Warsaw Univ. of Technology, Poland

\begin{abstract}
The works on this subject usually refer to the so-called. averaged spectra. The authors try to bypass the problem of inflating the spectra that result from other structure fluctuations which occur in each of the measuring device. The minimum particle spectrum of primary cosmic rays will be presented. The chemical composition of this radiation will be discussed.

See references [1-9]
\end{abstract}

\section{References}

[1] E.G. Berezhko, Advances in Space Research 41 (2008) 429-441

[2] E.S. Seo, V.S. Ptuskin, Astrophysical Journal 431 (1994) 705-714

[3] V. Berezinsky, A. Gazizov, S. Grigorieva, Phys. Rev. D. (2006) 74043005

[4] A. Garyaka et al, ISVHECRI Berlin 2012

[5] V. Ptuskin, V. Zirakashvilu, E.S. Seo, Astrophysical Journal 718 (2010) 31-36

[6] E.G. Berezhko, S.P. Knurenko, L.T. Ksenofontov, Astroparticale Physics 36 (2010) 31-36

[7] E.G. Berezhko, H. Voelk, Astrophysical Journal 661 (2007) L175-L178

[8] Y.S. Yoon et al, arXiv:1102.2575v1 [astro-ph.HE] 13 Feb 2011

[9] A.D. Panov et al, Bulletin of the Russian Academy of Sciences Physics 71 No 4 (2007) 494-497

Slides

The slides of the talk can be found on the website of the symposium ISVHECRI 2012:

https://indico.desy.de/conferenceOtherViews.py?view=standard\&confId=4594

a kempa@pw.plock.pl

This is an Open Access article distributed under the terms of the Creative Commons Attribution License 2.0, which permits unrestricted use, distribution, and reproduction in any medium, provided the original work is properly cited. 